Submission ID: 43898

\title{
Results of Combined Investigations of Domanic Formation with Continuous Thermal Core Profiling
}

E.Y. Popov* (Skolkovo Institute of Science and Technology), Y.A. Popov (Skolkovo Institute of Science and Technology), A.V. Gabova (Skolkovo Institute of Science and Technology), E.M. Chekhonin (Skolkovo Institute of Science and Technology), R.A. Romushkevich (Skolkovo Institute of Science and Technology), M.Y. Spassenykh (Skolkovo Institute of Science and Technology), V. P Stenin (Skolkovo Institute of Science and Technology), E.Y. Kozlova (Skolkovo Institute of Science and Technology), S.V. Deliya (Ritek JC), T.R. Shayakhmetov (Ritek JC), K.A. Drandusov (Ritek JC)

\section{SUMMARY}

For the first time, a detailed study of thermal properties (thermal conductivity, volumetric heat capacity, thermal anisotropy and heterogeneity coefficients) of Domanic formation rocks was carried out using the method of continuous non-contact thermal core profiling. Results of the study showed that core samples of Domanic formation are characterized by significant multi-scale heterogeneity and anisotropy. Based on the results of thermal conductivity profiling, continuous high-resolution $(1 \mathrm{~mm})$ profiles of total organic carbon (TOC) were obtained, that significantly extended and enriched the results of pyrolysis. Close correlations between thermal conductivity and density, thermal conductivity and sonic velocities were established with the use of well logging data. It allows predicting of rock mechanical properties without core destruction independently of sonic logging data quality (wellbore walls condition, etc.). Detailed profiles of geomechanical properties were reconstructed through established correlations and successfully compared with results of sonic logging along a studied section of Domanic formation. Conducted study shows that combination of traditional study and express high-resolution non-contact thermal core profiling makes it possible to optimize sample collection for laboratory study and characterize formation by high-resolution profiles of different properties of Domanic formation rocks. 
Результаты комплексных исследований доманиковой формации путем непрерывного теплофизического профилирования керна

Попов Е.Ю., Попов Ю.А., Габова А.В., Чехонин Е.М., Ромушкевич Р.А., Спасенных М.Ю., Стенин В.П. (Сколтех), Делия С.В., Шаяхметов Т.Р., Драндусов К.А. (АО «РИТЭК»)

Впервые в геолого-геофизической практике проведены детальные исследования комплекса тепловых свойств пород доманиковой формации на территории Самарской области на лицензионных участках АО «РИТЭК». Работы выполнялись методом непрерывного бесконтактного профилирования тепловых свойств на керне [1-4]. Для скважины Добрынинского месторождении изучено 16,9 м полноразмерного керна (167 образцов), для скважины Западно-Авралинское месторождения - 21,9 м (200 образцов). Для каждого образца керна с пространственным разрешением $\sim 1$ мм регистрировались профили главного значения тензора теплопроводности $\lambda_{/ /}$вдоль напластования, профили объемной теплоемкости $C$, определялись главное значение тензора теплопроводности $\lambda_{\perp}$ перпендикулярно напластованию, коэффициент тепловой анизотропии $K$, коэффициент тепловой неоднородности $\beta$, характеризующий структурно-текстурные особенности пород вдоль оси керна $\left(\beta_{\|}\right)$и в перпендикулярном направлении $\left(\beta_{\perp}\right)$ [1]. Результаты профилирования для месторождений приведены на рисунках 1 и 2 . Основная погрешность измерений (при доверительной вероятности 0,95$)$ составляла $\pm 3 \%$ для теплопроводности $\lambda_{\|}, \pm 4 \%$ для теплопроводности $\lambda_{\perp}, \pm 5$ для объемной теплоемкости [1].

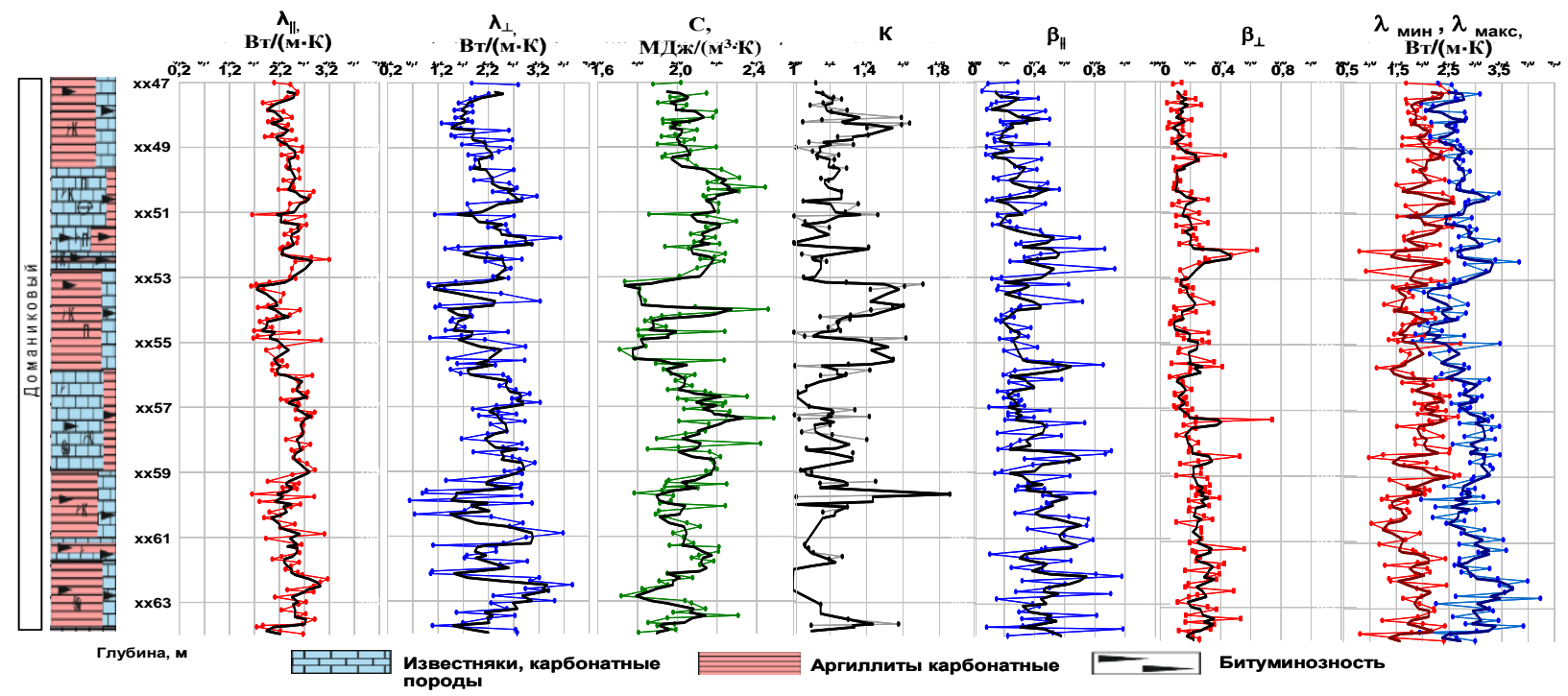

Рисунок 1. Результаты исследований тепловых свойств пород месторождения Добрынинское (пояснения даны в тексте). На левой панели красным цветом показаны результаты измерений параметра $\lambda_{\|}$, синим - параметра $\lambda_{\perp}$; красным иветом показан коэффициент тепловой неоднородности образиов керна при теплофизическом профилировании вдоль оси керна, синим иветом - при профилировании поперек оси керна. Точками показаны средние значения изучавшихся параметров для каждого изучавшегося образиа керна, черные линии на всех панелях - результаты обработки данных сглаживаюшим прямоугольным фильтром с окном осреднения 3 элемента.

Целевое назначение результатов измерений теплофизического профилирования на керне формирование представительных баз исходных данных о тепловых свойствах пород и петрофизическое обоснование их использования для бассейнового моделирования и гидродинамического моделирования процессов тепло- и массопереноса в резервуарах при тепловых методах добычи, решения прямых задач термометрии скважин. 
За счет уникально высокого пространственного разрешения (1 мм) при теплофизическом профилировании керна и установленных связей типа «керн-ГИС» и «керн-керн» [2-4] возникают новые возможности этой технологии для оценки однородности кернового материала, что позволяет существенно дополнить возможности традиционного комплекса методов ГИС и лабораторной петрофизики [2-4].

Согласно данным на рисунках 1 и 2, значительные вариации теплопроводности и объемной теплоемкости характеризуют существенную неоднородность пород обоих разрезов. Данные о коэффициентах $\beta_{\|}$и $\beta_{\perp}$ свидетельствуют о серьезной неоднородности изучавшихся образцов пород, поскольку вариации теплопроводности в пределах образцов достигают 80-90\%, что в первую очередь отражает вариации $\mathrm{C}_{\text {орг }}$ в пределах образца керна, и при этом характеризуются четкой зональностью вдоль скважин [4]. Обращает на себя внимание существенная анизотропия пород (с коэффициентом анизотропии до 2,2) c ее четко выраженной зональностью вдоль скважин.

Использование данных теплофизического профилирования (как средства анализа неоднородности высокого разрешения) позволяет обеспечить обоснованный отбор образцов для стандартных и специальных исследований керна и дает возможность оценить погрешности при использовании стандартной методики отбора образцов на исследования.

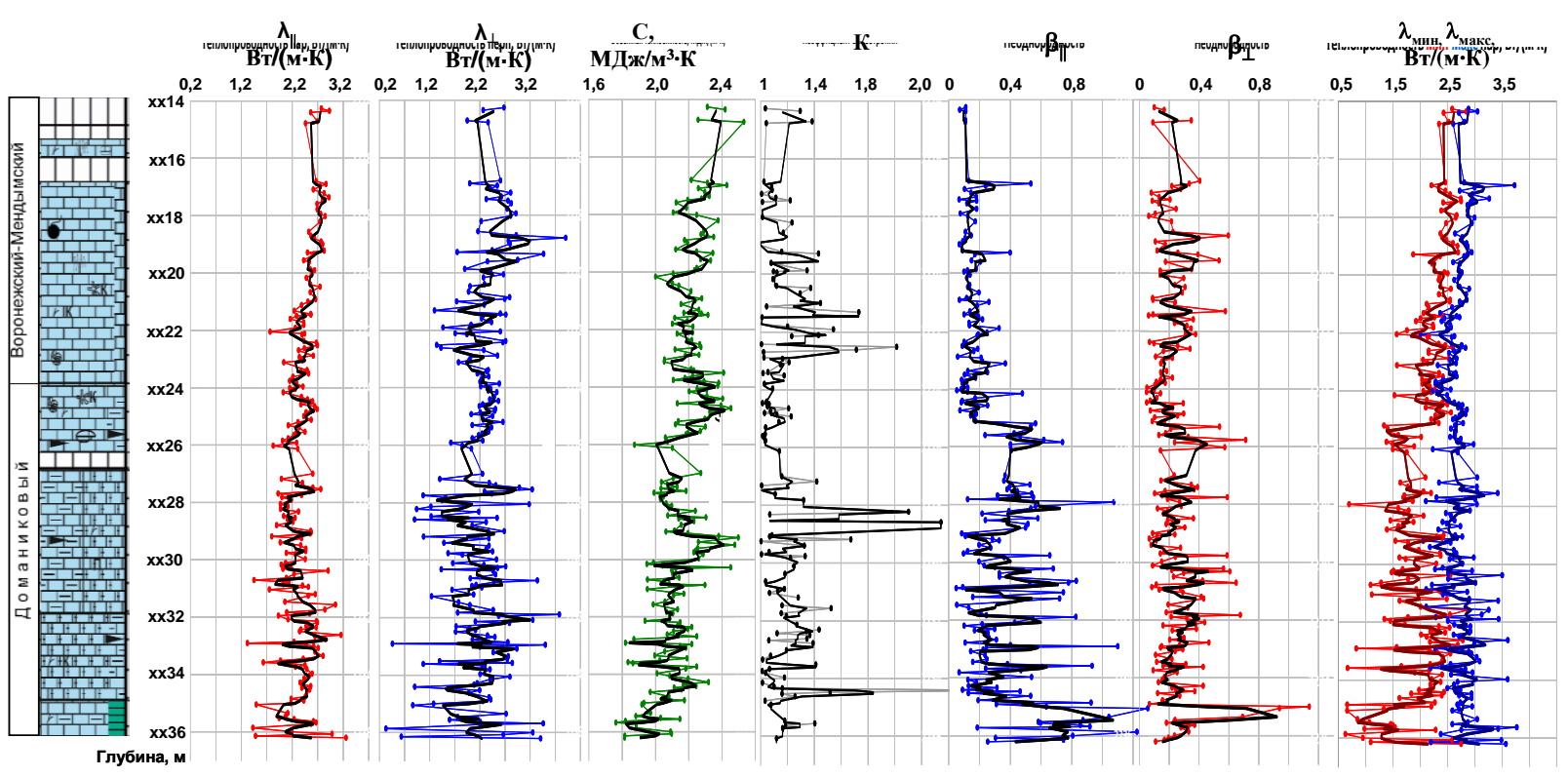

Рисунок 2. Результаты исследований тепловых свойств пород месторождения ЗападноАвралинское.

На рисунке 3 приведены детальные профили теплопроводности $\lambda_{\|}$, которые предоставляют уникальную возможность характеризовать разномасштабную неоднородность разрезов, начиная от масштаба в $\sim 1$ мм (случайная погрешность определения теплопроводности $\pm 1,5 \%$ при доверительной вероятности 0,95), Данные на рисунках 1-3 свидетельствуют о существенной неоднородности разрезов, которая проявляется на масштабах, начиная с первых миллиметров, что связано со значительными вариациями общего содержания органического вещества $C_{\text {орг. }}$ Разработанные подходы [3-4] обеспечивают регистрацию детальных профилей $C_{\text {op }}$ по результатам профилирования теплопроводности (рисунок 4), что существенно дополняет данные по $C_{\text {орг }}$, обычно получаемые путем пиролиза (рисунок 4).

Сочетание профилирования тепловых свойств, стандартных профильных исследований и материалов ГИС позволило установить важные корреляции между тепловыми и другими свойствами пород. Так, установлены тесные корреляционные связи теплопроводности с 


\section{EAGE}

плотностью $(\rho)$ и скоростями продольной $\left(\mathrm{V}_{\mathrm{p}}\right)$ и поперечной $\left(\mathrm{V}_{\mathrm{s}}\right)$ упругих волн, что позволяет по известным формулам рассчитать динамические модуль Юнга (Е) и коэффициент Пуассона (v) [3]. В результате это обеспечивает детальный прогноз упругих параметров (вплоть до миллиметрового масштаба) на основе данных непрерывного профилирования на керне. Возможность осуществления такого прогноза зависит лишь от наличия керна и не зависит от состояния стенок скважины и других причин, затрудняющих или делающих невозможным интерпретацию данных акустического каротажа, что повышает качество данных об упругих параметрах пород доманиковой свиты. Соответствующий пример использования результатов теплофизического профилирования на керне для определения геомеханических характеристик показан на рисунке 5.

Предложенный теплофизический подход к анализу свойств пород разреза, характеризуемый в настоящее время производительностью около 20 метров в день и полным отсутствием механического воздействия на образцы керна, обеспечивает качественно новый уровень детализации информации по исследуемым коллекторам, возможность проведения экспрессисследований как в кернохранилище, так и на скважине, возможность оптимизации отбора образцов для специальных исследований, возможность замещения технологии скретчирования, сокращение затрат на анализ керна. Приведенные результаты теплофизических исследований показывают необходимость проведения систематических исследований пород путем теплофизического профилирования керна применительно к различным задачам поиска, разведки и разработки месторождений углеводородов в доманиковой формации.

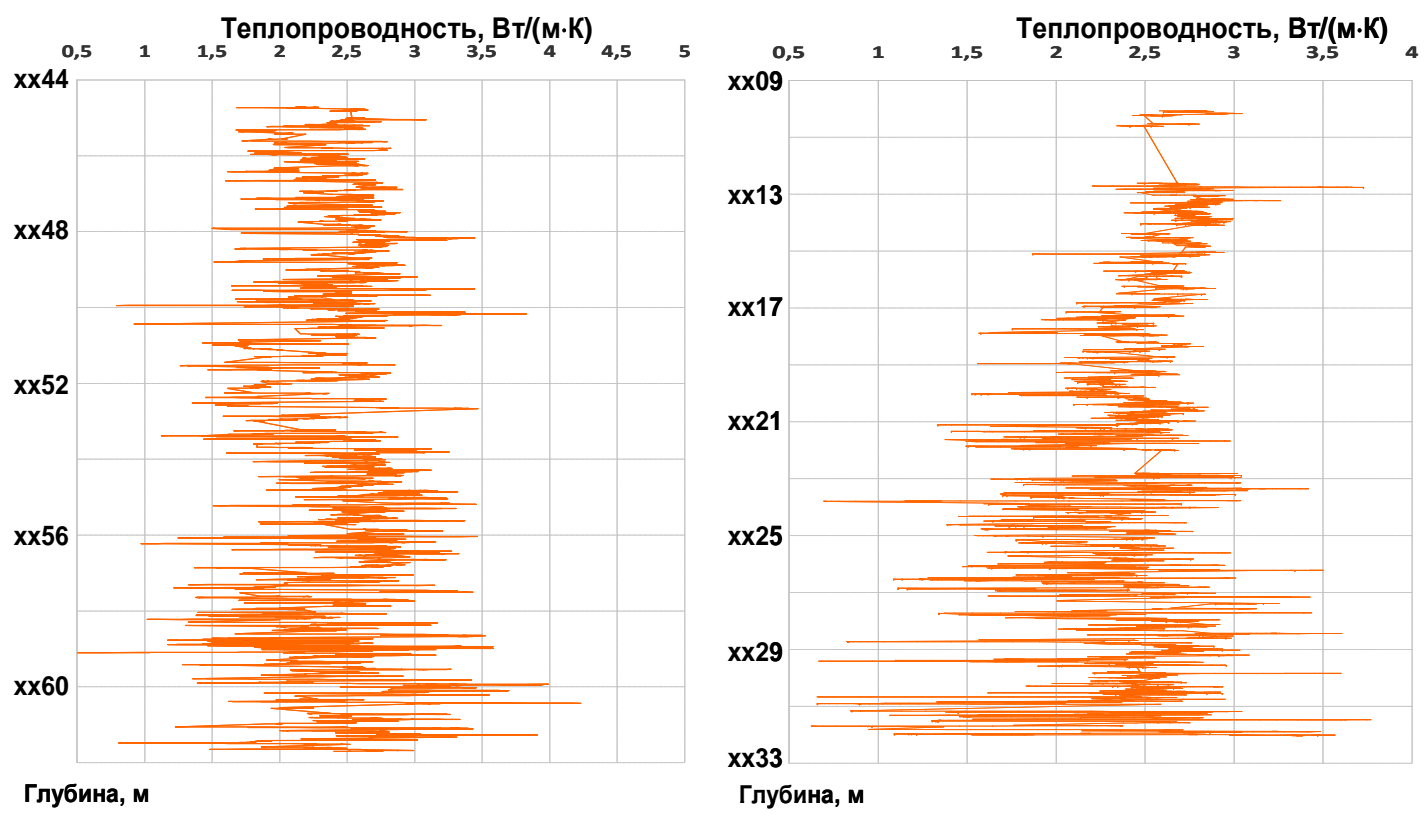

Рисунок 3. Результаты непрерывного профилирования теплопроводности $\lambda_{\|}$(левая панель Добрынинское месторождение, правая панель - Западно-Авралинское месторождении). 


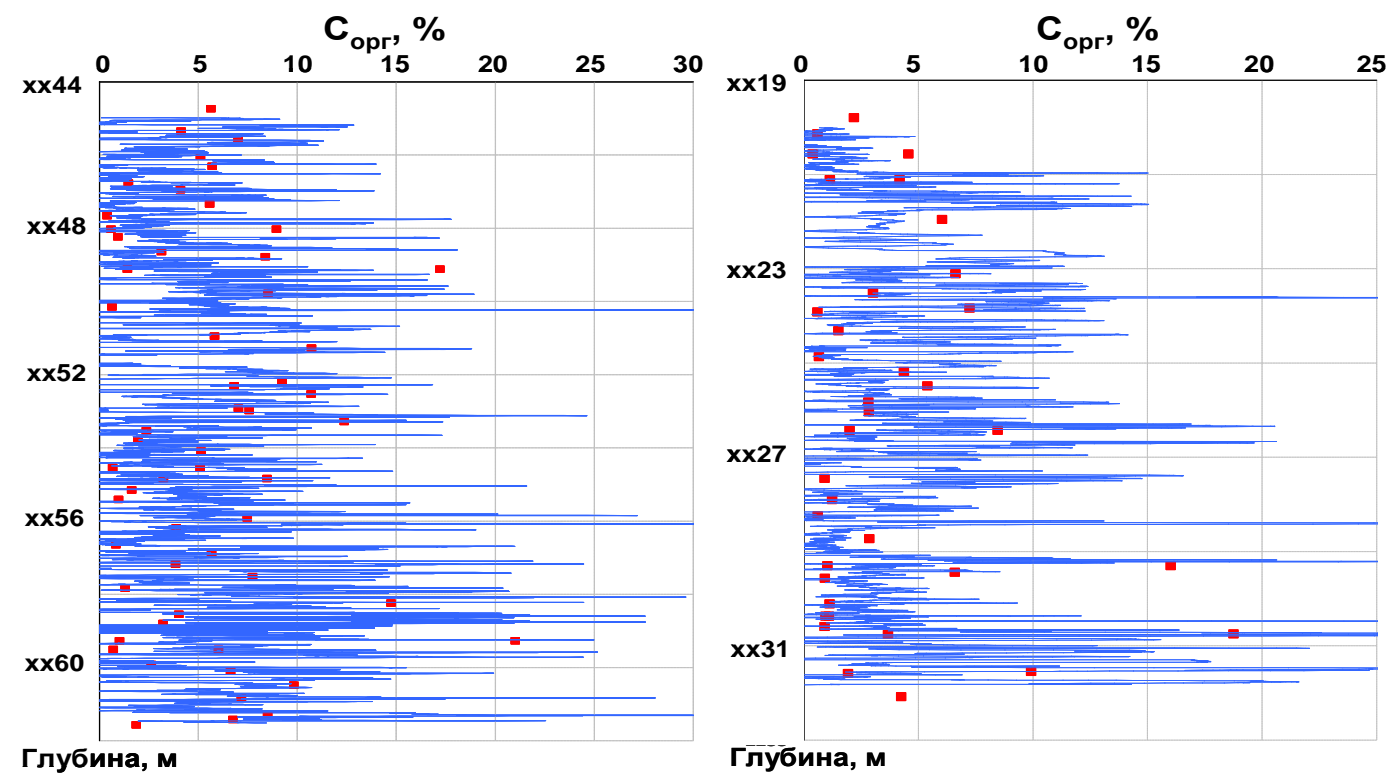

Рисунок 4. Профили общего содержания органического вещества (синий ивет), полученные по результатам непрерывного профилирования теплопроводности $\lambda_{\|}$по керну (левая панель Добрынинское месторождение, правая панель - Западно-Авралинское месторождение). Красный ивет - результаты определения $C_{\text {орг }}$ путем пиролиза.
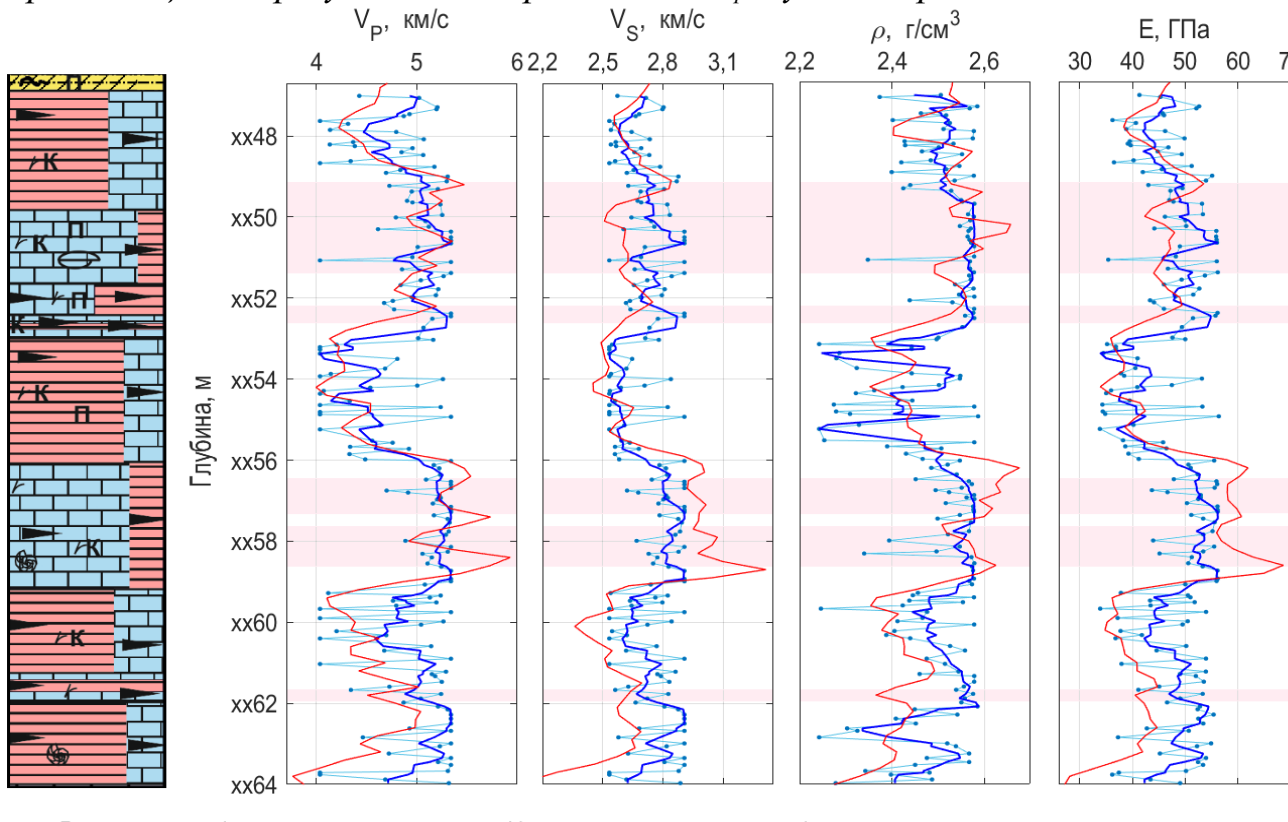

Данные по теплофизическому
профилированию для образцов керна -Усредненные данные по теплофизическому
профилированию $2,2 \quad 2,5 \quad 2,8 \quad 3,1$

Рисунок 5. Результать определения геомеханических характеристик по данным

Данные по акустическому каротажу

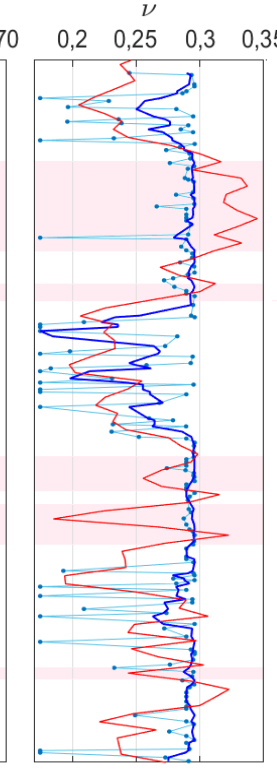

Размытие ствола скважины акустического, плотностного каротажа (красные кривые) и корреляционным зависимостям с теплопроводностью, измеренной на керне. Голубые точки - результаты определений геомеханических характеристик по теплопроводности для отдельных образиов керна, синие кривые - результаты усреднения данных, полученных для образиов керна, для приведения результатов к пространственной разрешающей способности акустического каротажа.

В результате работ показано, что сочетание стандартных исследований с экспрессным высокоразрешающим неразрушающим профилированием тепловых свойств пород с использованием установленных корреляций позволяет оптимизировать отбор образцов для лабораторных исследований и охарактеризовать разрез высокоразрешающими профилями целевых свойств пород доманиковой свиты. 


\section{Литература}

1. Popov Y., Beardsmore G., Clauser C., Roy S. ISRM Suggested methods for determining thermal properties of rocks from laboratory tests at atmospheric pressure. //Rock Mechanics and Rock Engineering, 2016, № 49(10), P. 4179-4207.

2. Попов Е.Ю., Чехонин Е.М., Ромушкевич Р.А., Сафонов С.С., Урсегов С.О, Гурбатова И.П.. 2016. Теплофизическое профилирование керна при доизучении геологического строения пермо-карбоновой залежи Усинского месторождения. //Известия высших учебных заведений. Серия Геология и разведка, 6, 38-49.

3. Попов Е.Ю., Чехонин Е.М., Попов Ю.А., Ромушкевич Р.А., Габова А.В., Жуков В.В. Новый подход к изучению баженовской свиты на основе теплофизического профилирования керна. //Недропользование XXI век. - 2016, 6., 52-61.

4. Попов Ю.А., Попов Е.Ю., Чехонин Е.М., Габова А.В., Ромушкевич Р.А., Спасенных М.Ю., Заграновская Д.Е. Исследования баженовской свиты с применением непрерывного профилирования тепловых свойств на керне. //Нефтяное хозяйство. 2017, 3, 23-27.

\section{References}

1. Popov Y., Beardsmore G., Clauser C., Roy S. ISRM Suggested methods for determining thermal properties of rocks from laboratory tests at atmospheric pressure. //Rock Mechanics and Rock Engineering, 2016, № 49(10), P. 4179-4207.

2. Popov E.Y., Chekhonin E.M., Romushkevich R.A., Safonov S.S., Ursegov S.O., Gurbatova I.P. 2016, Thermal core profiling at additional investigations of Usinsk oilfield geological structure. // Proceedings of Higher Schools, Journal "Geology and Exploration" \#6, p.38-49.

3. Popov E.Y., Chekhonin E.M., Popov Y.A., Romushkevich R.A., Gabova A.V., Zhukov V.V. Novel approach of Bazhenov formation investigation through thermal core profiling. //Nedropolzovanie XXI vek. - 2016, \#6, p.52-61.

4. Popov Y.A., Popov E.Y., Chekhonin E.M., Gabova A.V., Romushkevich R.A., Spasennykh M.Y. $\&$ Zagranovskaya D.E. Investigation of Bazhenov formation using thermal core logging technique. 2017, Neftyanoe Khozyaystvo - Oil Industry, \#3, pp. 22-27. 